\title{
Chemical Pre-Treatment of Anionic Surfactants Contaminated Waste Water at Enaspol A. S. using $\mathrm{H}_{2} \mathrm{O}_{2} / \mathrm{UV}$ Light Waste Water Pre-Treatment Method
}

\author{
Banyaladzi D. Paphane ${ }^{1 *}$ and Lisset L.Z. Ramirez ${ }^{2}$
}

${ }^{1}$ Botswana College of Agriculture, Department of Basic Sciences, Private Bag 0027, Gaborone, Botswana

${ }^{2}$ Mexico General Customs Administration, Central Administration of Customs Regulation, Mexico City, Mexico

\begin{abstract}
Close to $50 \%$ of anionic surfactants at Enaspol a. s., a chemical company with longtime tradition in research and production of surfactants, construction chemicals and textile auxiliaries, were removed from waste water using the Advanced Oxidation Method, $\mathrm{H}_{2} \mathrm{O}_{2} /$ Ultra-Violet Radiation waste water pre-treatment method. The optimum concentration of hydrogen peroxide was found to be $1.0 \mathrm{~g} / \mathrm{L} \mathrm{H}_{2} \mathrm{O}_{2}$ in waste water. Above this concentration, the excess hydrogen peroxide reacts with other contaminants, such as elemental sulfur in the waste water producing complex oxidizable material. The optimum time to remove maximum amounts of surfactants $(42.50 \%)$ was found to be three hours. Beyond three hours the efficiency of this method is reduced. The reduction of chemical oxygen demand shows a rather interesting pattern; there was an increase in removal of COD from 0 to $1.0 \mathrm{~g} / \mathrm{L} \mathrm{H}_{2} \mathrm{O}_{2}$ in waste water and from 1.0 $\mathrm{g} / \mathrm{L} \mathrm{H}_{2} \mathrm{O}_{2}$ there was a decrease in the reduction efficiency of COD by this method in waste water. This shows that excess $\mathrm{H}_{2} \mathrm{O}_{2}$ is reacting with other non-organic species such as sulphur in waste water to produce extra oxidizable material which contribute to the COD value.
\end{abstract}

Keywords: Advanced oxidation processes; Surfactants; Waste water; Chemical oxygen demand; Hydrogen peroxide; Ultra-Violet radiation

\section{Introduction}

The European Union Commission on the Environment sets targets and levels of pollutants for waste water. In 1991, The Council Directive (Directive 91/271/EEC and ENV.E.3/ETU/200/0058) concerning urban waste water treatment, sets guidelines for urban water treatment, where there is emphasis for secondary waste water treatment before discharge into water ways.

Four methods can be employed to achieve this: coagulation [1], adsorption [2], reverse osmosis [3] and chemical pre-treatment [4]. The problem with reverse osmosis is that even though it can remove as many contaminants as possible it is costly both to install and to run [5]. There are different kinds of chemical water pre-treatment methods used depending on the types of contaminants. For these kinds of contaminants, Advanced Oxidation Processes (AOPs) are proposed. The main function of AOP is the generation of highly reactive free radicals more especially the hydroxyl radical (HO). Hydroxyl radicals are effective in destroying organic chemicals because they react rapidly and non-selectively with nearly all electron rich organic compounds such as dyes, oils and surfactants [4].

There are three popular AOP processes used in industry for pretreatment of waste water overlain with organic contaminants: Titanium dioxide/Ultraviolet light $\left(\mathrm{TiO}_{2} / \mathrm{UV}\right)$, Hydrogen Peroxide/Ultraviolet light $\left(\mathrm{H}_{2} \mathrm{O}_{2} / \mathrm{UV}\right)$ and Fenton's reaction that is Ferrous ion/hydrogen Peroxide $\left(\mathrm{Fe}^{2+} / \mathrm{H}_{2} \mathrm{O}_{2}\right)$ methods. The efficiency of these methods is in their ability to produce hydroxyl radicals which scavenge organic compounds in waste water [4]

In the Titanium Dioxide/UV Light Process, during UV irradiation of $\mathrm{TiO}_{2}$, conduction band electrons (ecb) and valence band holes $\left(\mathrm{h}^{+}\right)$ are initially yielded. Band electrons interact with molecular oxygen producing superoxide radical anions. On the other hand band holes react with water molecules to yield hydroxyl radicals [5]. The advantage of this method is that the reaction takes place at ambient conditions. Titanium Dioxide act in this case as a catalyst which means it can be reused making the process cheaper. This method is capable of oxidizing a wide range of organic compounds into harmless compounds such as carbon dioxide and water [6]. On the other hand there is a need for uniform irradiation of UV light on the catalyst for the method to work. This means that the reactor should be designed in such a way that this is achieved. Waste water with other anionic species will also affect the degradation process as UV light will be absorbed by these competing species. These species will also compete with organic pollutants for the hydroxyl radicals. This is desirable in this case because there will be a reduction in Chemical Oxygen Demand (COD) concentration.

The Hydrogen Peroxide/UV Light Process involves the cleavage of oxygen-oxygen bonds in hydrogen peroxide by ultraviolet radiation to produce hydroxyl radicals [6]. The efficiency and advantages of this method are similar to that of the $\mathrm{TiO}_{2} / \mathrm{UV}$ light method since $\mathrm{H}_{2} \mathrm{O}_{2}$ is a cheap chemical and is readily available in the market. The only drawback with this method is that $\mathrm{H}_{2} \mathrm{O}_{2}$ has a poor UV light absorption characteristics. Therefore if water matrix will absorb a lot of UV light energy, most of the light input will be wasted.

The Fenton's reactions $\left(\mathrm{Fe}^{2+} / \mathrm{H}_{2} \mathrm{O}_{2}\right.$ process), offers the same kinds of advantages as the first two methods. In addition, the requirement for special kind of light (UV) is removed which means that the cost is further reduced. The disadvantage of this method is that it works better in acidic solutions. The addition of ferrous ions to the waste water

*Corresponding author: Banyaladzi D. Paphane, Botswana College of Agriculture, Basic Sciences Department, Private Bag 0027, Gaborone, Botswana Tel: +26773491837; E-mail: docpapb@gmail.com, bpaphane@bca.bw

Received May 29, 2013; Accepted June 27, 2013; Published July 01, 2013

Citation: Paphane BD, Ramirez LLZ (2013) Chemical Pre-Treatment of Anionic Surfactants Contaminated Waste Water at Enaspol A. S. using $\mathrm{H}_{2} \mathrm{O}_{2} / \mathrm{UV}$ Light Waste Water Pre-Treatment Method. J Environ Anal Toxicol 3: 181. doi:10.4172/21610525.1000181

Copyright: (c) 2013 Paphane BD, et al. This is an open-access article distributed under the terms of the Creative Commons Attribution License, which permits unrestricted use, distribution, and reproduction in any medium, provided the original author and source are credited. 
may prove to add some more unwanted material hence it is highly discouraged as a pre-treatment method.

In ENASPOL A. S. "A chemical company with longtime tradition in research and production of surfactants, construction chemicals (mainly concrete plasticizers) and textile auxiliaries", the waste water from the production plant is generated from a large number of raw materials and finished products; this is mainly due to dripping, steaming of filling hoses or by machinery wash outs. The industrial sectors such as Enaspol a. s. which produces biodegradable industrial waste water not entering urban waste water treatment plants before discharge to receiving waters should be subject to appropriate requirements and legislation. These contaminated waters are accumulated in a basin (holding tank of about $200 \mathrm{~m}^{3}$ ) and then pumped over to the Biological Waste Water Treatment Plant (BWWTP), where biological decomposition of the waste contained in the waste water takes place (Metcalf and Eddy INC., 1972). After biological treatment, the water is discharged into the nearby river. Enaspol a. s. is allowed by the Czech government to discharge waste water containing a maximum of $4 \mathrm{mg} / \mathrm{L}$ of surfactants and maximum of $200 \mathrm{mg} / \mathrm{L}$ chemical oxygen demand (COD).

Currently the holding tank contains waste water with approximately $1358 \mathrm{mg} / \mathrm{L}$ of anionic surfactants and approximately $9558 \mathrm{mg} / \mathrm{L} \mathrm{COD}$ raising the $\mathrm{pH}$ of the water to about 10.30 (Enaspol June 2011 quality control results); this means that the waste water reaching BWWTP is overlain with these biodegradable contaminants. Therefore more time should be allowed for biological decomposition of waste water to reach the allowed limits or worse still the water should be diluted before draining to the BWWTP. This means that discharge of waste water from the plant to the holding tank and hence to the BWWTP should be delayed. This has an effect on production as delay in waste water treatment means delay in production. The other problem is that with high load of contaminants in the BWWTP there is a high possibility of contaminants leaving BWWTP into the river. The only feasible solution is to reduce the burden in the waste waters in the holding tank prior to their transfer to the BWWTP. The aim of this study was to optimize the Hydrogen Peroxide/UV Light waste water treatment process for the treatment of anionic surfactant contaminated waste water at Enaspol A. S., thereby reducing COD concentration in the wastewater prior to discharge in the BWWTP.

\section{Optimization of Parameters for Hydrogen Peroxide/UV Light Process}

The aims of this study are to optimize the concentration of $\mathrm{H}_{2} \mathrm{O}_{2}$ and residence time of the system for this process to be effective.

\section{Concentration of $\mathrm{H}_{2} \mathrm{O}_{2}$}

As noted earlier hydrogen peroxide has poor ultra violet light absorbance characteristics. Again if more $\mathrm{H}_{2} \mathrm{O}_{2}$ reaches the BWWTP tank it might affect the efficiency of the micro-organisms there $[7,8]$. This might not be the case for this system since there is aeration in the BWWTP which might decompose the hydrogen peroxide. Therefore there is need to investigate the optimum concentration of $\mathrm{H}_{2} \mathrm{O}_{2}$ for the Enaspol system.

\section{Residence time for the system}

One bottleneck that pre-treatment of waste water pose is the time waste water stays in the holding tank. If the time taken for pre-treatment is the same as the time taken for micro-organisms to degrade wastes, then there is no need for pre-treatment. It is therefore important that the system is effective and has a low turnaround time.

\section{Materials and Methods}

\section{Waste water sample collection and analysis}

The surfactants contaminated waste water was collected from the $200 \mathrm{~m}^{3}$ Enaspol a. s. waste water holding tank. The water was stirred during sampling to get a homogenous sample. The samples were taken to the laboratory in sealed plastic containers in a cooler box with ice cubes to minimise auto-degradation. Samples were used and analysed immediately in triplicates upon reaching the laboratory. A fresh sample of about one litre was obtained each time an experiment was done. A commercially available 30 V GPH212 Germicidal Ultra-Violet lamp was used as a UV light source. The initial pH of the sample was determined by a Mettler Toledo multi-parameter bench meter equipped with a $\mathrm{pH}$ probe, the $\mathrm{COD}$ and anionic surfactant concentrations were determined following standard methods for the examination of water and wastewater $[9,10]$.

\section{Investigation of optimum $\mathrm{H}_{2} \mathrm{O}_{2}$ concentration}

A laboratory reactor was designed by a schematic diagram (Figure 1). The reactor is a closed metal box equipped with a magnetic stirring hot plate. Surfactant contaminated waste water $(400 \mathrm{~mL})$ was put into a $500 \mathrm{~mL}$ beaker and continuously stirred throughout the entire length of the experiment (Figure 2). The reactor was closed and all holes sealed with an opaque tape throughout the experiment to keep sunlight away.

Six solutions of different $\mathrm{H}_{2} \mathrm{O}_{2}$ concentration in waste water were prepared in triplicates: $0.5 \mathrm{~g} / \mathrm{L}, 1.0 \mathrm{~g} / \mathrm{L}, 2.0 \mathrm{~g} / \mathrm{L}, 3.0 \mathrm{~g} / \mathrm{L}, 4.0 \mathrm{~g} / \mathrm{L}$, and 5.0 $\mathrm{g} / \mathrm{L}$. The solutions were transferred into $500 \mathrm{~mL}$ beakers. The solutions were homogenised by continuous stirring with a magnetic stirrer throughout the trials. A $30 \mathrm{~V}$ Ultraviolet Lamp was switched on and the reaction was monitored for one hour. After one hour, the solutions were measured for COD and anionic surfactants content $[9,10]$.

\section{Investigation of optimal time for pre-treatment}

For the investigation of the optimal time for pre-treatment of the waste water, the same procedure was performed as above; in this case, the concentration of $\mathrm{H}_{2} \mathrm{O}_{2}$ was kept constant at $1.0 \mathrm{~g} / \mathrm{L}$ of $\mathrm{H}_{2} \mathrm{O}_{2}$ in waste water and the reaction time was varied from 1 hour to 4 hours at 1 hour intervals. After each hour samples were taken to the quality control laboratory for COD and anionic surfactants analysis.

\section{Results and Discussion}

Effects of hydrogen peroxide concentration on COD and anionic surfactants concentration reduction

The effect of increase in hydrogen peroxide dose on the reduction of surfactants and chemical oxygen demand (COD) concentrations is shown in Table 1 and Figure 3. The reduction of surfactant concentration

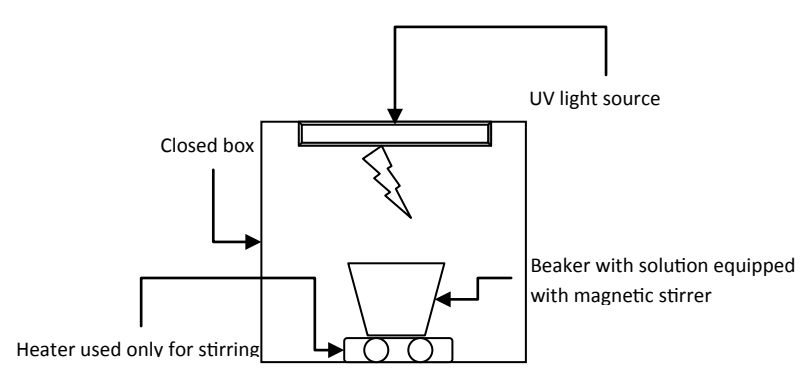

Figure 1: Schematic diagram of the reactor used. 
increased with an increase in the concentration of hydrogen peroxide from $0.5 \mathrm{~g} / \mathrm{L} \mathrm{H}_{2} \mathrm{O}_{2}$ to $5 \mathrm{~g} / \mathrm{L} \mathrm{H}_{2} \mathrm{O}_{2}$ in waste water. The highest amount removed was $14.66 \%$ for $5 \mathrm{~g} / \mathrm{L} \mathrm{H}_{2} \mathrm{O}_{2}$ in waste water. The reduction of chemical oxygen demand shows a rather interesting pattern; there was an increase in removal of COD from 0 to $1.0 \mathrm{~g} / \mathrm{L} \mathrm{H}_{2} \mathrm{O}_{2}$ in waste water and above 1.0 to $5.0 \mathrm{~g} / \mathrm{L} \mathrm{H}_{2} \mathrm{O}_{2}$ there was a decrease in the reduction efficiency of COD by this method in waste water. This is similar to what was published by other authors on a different system, who found out that as the concentration of $\mathrm{H}_{2} \mathrm{O}_{2}$ increases there is an increase in reduction of COD concentration to a certain extent and then the concentration starts decreasing [11]. After the addition of about 2.5 $\mathrm{g} / \mathrm{L}_{2} \mathrm{O}_{2}$ it shows that the COD concentration has increased from the original value as shown by negative percentage reduction in Figure 4 .

This shows that excess $\mathrm{H}_{2} \mathrm{O}_{2}$ is reacting with other non-organic species in waste water to produce extra oxidizable material which contribute to the COD value. This is expected since elemental sulphur is one of the major reactants for the system. It is expected that oxidation of elemental sulphur will produce $\mathrm{SO}_{\mathrm{x}}$ species [9]. The results showed that the optimum concentration of $\mathrm{H}_{2} \mathrm{O}_{2}$ for the reduction of COD in Enaspol a. s. waste water was $1.0 \mathrm{~g} / \mathrm{L} \mathrm{H}_{2} \mathrm{O}_{2}$ in waste water.

\section{Effects of the reaction time on COD and anionic surfactants concentration reduction}

Table 2 and Figure 4 show the relationship between time and percentage reduction of COD and anionic surfactants in waste water. The graph shows that there was an increase in percentage reduction of both COD and surfactant concentration in waste water from 0 to 3 hours of the reaction; after three hours there is a decrease in percentage reduction of these parameters. About half of the surfactants concentration (42.50 $\%$ ) is removed from waste water within three hours. This suggests that this method can be employed as a pre-treatment method for surfactant contaminated waste waters. This may reduce the strain on the BWWTP hence leading to an increased efficiency in cleaning waste water at Enaspol a. s. and any other similar system. On the other hand even though there is close to $50 \%$ reduction in anionic surfactants it shows that this has minimal impact in COD reduction. This shows that there are some oxidisible inorganic contaminants in the waste water which contribute significantly to COD concentration even higher that what the surfactants contributes.

\section{Conclusion}

Hydrogen Peroxide/UV light advanced oxidation method for the

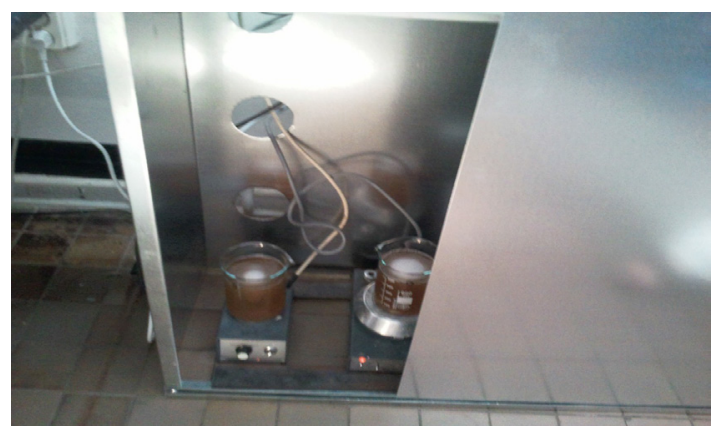

Figure 2: Picture of the reactor (open) during waste water pre-treatment.

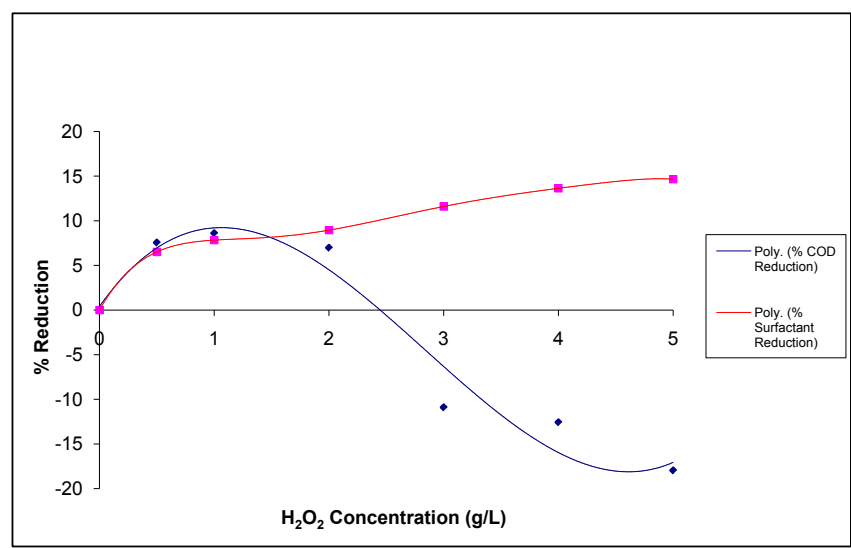

Figure 3: Effect of $\mathrm{H}_{2} \mathrm{O}_{2}$ concentration on the reduction of COD and surfactants concentration in waste water.

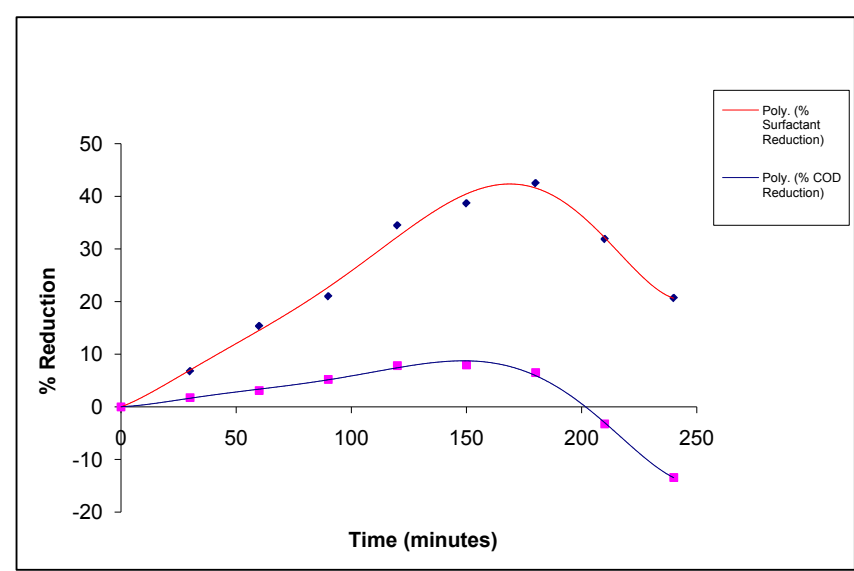

Figure 4: Effect of time on the reduction of COD and surfactants concentration from waste water using $1.0 \mathrm{~g} / \mathrm{L}$ of $\mathrm{H}_{2} \mathrm{O}_{2}$.

pre-treatment of waste water at Enaspol a. s. was found to be effective for the reduction of surfactants concentrations in waste water. The optimum concentration of hydrogen peroxide was found to be $1.0 \mathrm{~g} / \mathrm{L}$ $\mathrm{H}_{2} \mathrm{O}_{2}$ per liter of waste water and allowed to react for three hours. Above this concentration hydrogen peroxide is found to react in-situ with some inorganic contaminants in the waste water to produce some complex oxidisable contaminants which increase the COD concentration of the waste water.

On the other hand this method is found to have little effect on the reduction of total oxidisable species in the waste water. This means that Enaspol a. s. waste water contain in addition to surfactants, oxidisable inorganic species which contribute a great deal to the chemical oxygen demand of the waste water. This is expected since Enaspol a. s. produces other products which require other types of formulations different from those for producing surfactants. For increased efficiency of the system, there is need to determine the identity of other oxidisable species in the waste water.

\section{Acknowledgments}

The authors wish to thank the Organization for the Prohibition of Chemical Weapons (OPCW) and Enaspol a. s. management for financial and technical assistance rendered towards this project. 
Citation: Paphane BD, Ramirez LLZ (2013) Chemical Pre-Treatment of Anionic Surfactants Contaminated Waste Water at Enaspol A. S. using $\mathrm{H}_{2} \mathrm{O}_{2} /$ UV Light Waste Water Pre-Treatment Method. J Environ Anal Toxicol 3: 181. doi:10.4172/2161-0525.1000181

Page 4 of 4

\begin{tabular}{|c|c|c|c|c|c|c|}
\hline Time (hours) & Conc of $\mathrm{H}_{2} \mathrm{O}_{2}(\mathrm{~g} / \mathrm{l})$ & Average COD mg/L & $\begin{array}{c}\text { Average Surfactants } \\
\mathrm{mg} / \mathrm{L}\end{array}$ & Conc of $\mathrm{H}_{2} \mathrm{O}_{2}(\mathrm{~g} / \mathrm{L})$ & $\%$ COD reduction & $\begin{array}{c}\% \text { Surfactant } \\
\text { Reduction }\end{array}$ \\
\hline 0 & 0 & 10,898 & 982 & 0 & 0.00 & 0.00 \\
\hline 1 & 0.5 & 10,074 & 918 & 0.5 & $7.56 \pm 0.07$ & $6.52 \pm 0.12$ \\
\hline 2 & 1.0 & 9,960 & 905 & 1.0 & $8.61 \pm 0.11$ & $7.84 \pm 0.09$ \\
\hline 3 & 2.0 & 10,136 & 894 & 2.0 & $6.99 \pm 0.13$ & $8.96 \pm 0.13$ \\
\hline 4 & 3.0 & 12,086 & 868 & 3.0 & $-10.90 \pm 0.12$ & $11.61 \pm 0.10$ \\
\hline 5 & 4.0 & 12,267 & 848 & 4.0 & $-12.56 \pm 0.07$ & $13.65 \pm 0.12$ \\
\hline 6 & 5.0 & 12,855 & 838 & 5.0 & $-17.96 \pm 0.14$ & $14.66 \pm 0.05$ \\
\hline
\end{tabular}

Table 1: Effect of $\mathrm{H}_{2} \mathrm{O}_{2}$ concentration on the reduction of $\mathrm{COD}$ and surfactants concentration in waste water.

\begin{tabular}{|c|c|c|c|c|c|}
\hline \multirow[b]{2}{*}{ Time (min) } & \multicolumn{2}{|c|}{$0.5 \mathrm{mg} / \mathrm{L} \mathrm{H}_{2} \mathrm{O}_{2}$} & \multirow{2}{*}{ Time (min) } & \multicolumn{2}{|c|}{$1.0 \mathrm{mg} / \mathrm{L} \mathrm{H}_{2} \mathrm{O}_{2}$} \\
\hline & $\%$ Surfactants Reduction & $\%$ COD Reduction & & $\%$ Surfactants Reduction & $\%$ COD Reduction \\
\hline 0 & 0.00 & 0.00 & 0 & 0.00 & 0.00 \\
\hline 30 & $3.15 \pm 0.10$ & $1.45 \pm 0.09$ & 30 & $6.75 \pm 0.08$ & $1.76 \pm 0.12$ \\
\hline 60 & $6.52 \pm 0.05$ & $2.05 \pm 0.12$ & 60 & $15.36 \pm 0.12$ & $3.11 \pm 0.09$ \\
\hline 90 & $8.50 \pm 0.11$ & $2.65 \pm 0.05$ & 90 & $21.01 \pm 0.07$ & $5.21 \pm 0.10$ \\
\hline 120 & $10.34 \pm 0.07$ & $3.25 \pm 0.07$ & 120 & $34.48 \pm 0.13$ & $7.84 \pm 0.09$ \\
\hline 150 & $12.01 \pm 0.12$ & $4.00 \pm 0.11$ & 150 & $38.67 \pm 0.06$ & $7.98 \pm 0.05$ \\
\hline 180 & $13.89 \pm 0.04$ & $5.94 \pm 0.06$ & 180 & $42.50 \pm 0.13$ & $6.51 \pm 0.07$ \\
\hline 210 & $10.23 \pm 0.11$ & $5.44 \pm 0.11$ & 210 & $31.89 \pm 0.06$ & $-3.23 \pm 0.08$ \\
\hline 240 & $8.95 \pm 0.09$ & $5.16 \pm 0.09$ & 240 & $20.68 \pm 0.06$ & $-13.42 \pm 0.12$ \\
\hline
\end{tabular}

Table 2: Effect of time on the reduction of COD and surfactants concentration from waste water using 0.5 and $1.0 \mathrm{~g} / \mathrm{L} \mathrm{of} \mathrm{H}_{2} \mathrm{O}_{2}$.

\section{References}

1. Rodriguez J, Stopić S, Krause G, Friedrich B (2007) Feasibility Assessment of Electrocoagulation towards a New Sustainable Wastewater Treatment. Environmental Science and Pollution Research 14: 477-482.

2. Allen SJ, Koumanova B (2005) Decolouration of water/waste water using adsorption. Journal of the University of Chemical Technology and Metallurgy 40: 175-192.

3. Wilf M, Alt S (2000) Application of low fouling RO membrane elements for reclamation of municipal wastewater. Desalination 132: 11-19.

4. Stasinakis AS (2008) Use of selected advanced oxidation processes (AOPs) for waste water treatment-A mini review. Global NEST Journal 10: 376-385.

5. Crittenden JC, Trussell RR, Hand DW, Howe KJ, Tchobanoglous G (2005) Water treatment: Principles and Design, $2^{\text {nd }}$ edn, John Wiley and Sons, New Jersey.
6. Chatterjee D, Dasgupta S (2005) Visible light induced photocatalytic degradation of organic pollutants. J Photochem Photobiol 6: 186-205.

7. Metcalf, Eddy, Tchobanoglous G (1972) Wastewater Engineering: Treatment disposal reuse. McGraw-Hill Book Company 552-554.

8. Lagrange J, Pallares C, Wenger G, Lagrange P (1993) Electrolyte effects on aqueous atmospheric oxidation of sulphur dioxide by hydrogen peroxide. Atmospheric Environment 27: 129-137.

9. International Standard, ISO 6060 (1989) Water Quality Determination of Chemical Oxygen Demand, 2nd Edn. 10-15

10. Mahvi AH, Bazrafshan E, Jahed GR (2005) Evaluation of COD Determination by ISO 6060 Method, comparing with Standard Method (5220, B). Pak J Bio Sci 8: 892-894.

11. Rehman MSU, Ahmad N, Yasar A, Sarwar M, Muhammad A (2006) Application of $\mathrm{H} 2 \mathrm{O} 2$, UV \& UV/H2O2 Systems for the Post Treatment of Bio-treated Industrial Wastewater. Electronic Journal of Environmental, Agricultural and Food Chemistry 5: 1575-1582. 